\title{
Mutational analysis of Peroxiredoxin IV: exclusion of a positional candidate for multinodular goitre Emiliano Giardina1 ${ }^{1}$, Francesca Capon ${ }^{1}$, M Rosaria D'Apice ${ }^{1}$, Francesca Amati ${ }^{1}$, Franco Arturi ${ }^{2}$, Sebastiano Filetti ${ }^{2}$, Emanuela Bonifazi ${ }^{1}$, Sabina Pucci ${ }^{1}$, Chiara Conte ${ }^{1}$ and Giuseppe Novelli*1
}

Address: ${ }^{1}$ Department of Biopathology, "Tor Vergata" University of Rome, Italy and ${ }^{2}$ Department of Experimental Medicine, University of Catanzaro, Italy

E-mail: Emiliano Giardina - emizago@yahoo.com; Francesca Capon - Capon@med.uniroma2.it; M Rosaria D'Apice - dapice2@yahoo.it; Francesca Amati - amati@med.uniroma2.it; Franco Arturi - arturi@unicz.it; Sebastiano Filetti - filetti@tin.it;

Emanuela Bonifazi - emanuelabonifazi@yahoo.it; Sabina Pucci - sabina.pucci@infos1.casaccia.enea.it; Chiara Conte - chiaraconte@yahoo.it; Giuseppe Novelli* - novelli@med.uniroma2.it

${ }^{*}$ Corresponding author

Published: 23 July 2002

BMC Medical Genetics 2002, 3:5

This article is available from: http://www.biomedcentral.com/I47/-2350/3/5
Received: 2 May 2002

Accepted: 23 July 2002

(c) 2002 Giardina et al; licensee BioMed Central Ltd. Verbatim copying and redistribution of this article are permitted in any medium for any purpose, provided this notice is preserved along with the article's original URL.

\begin{abstract}
Background: Multinodular goitre (MNG) is a common disorder characterised by an enlargement of the thyroid, occurring as a compensatory response to hormonogenesis impairment. The incidence of MNG is dependent on sex (female:male ratio 5:1) and several reports have documented a genetic basis for the disease. Last year we mapped a MNG locus to chromosome Xp22 in a region containing the peroxiredoxin IV (Prx-IV) gene. Since Prx-IV is involved in the removal of $\mathrm{H}_{2} \mathrm{O}_{2}$ in thyroid cells, we hypothesize that mutations in Prx-IV gene are involved in pathogenesis of MNG.

Methods: Four individuals ( 2 affected, 2 unrelated unaffected) were sequenced using automated methods. All individuals were originated from the original three-generation Italian family described in previous studies. A Southern blot analysis using a Prx-IV full-length cDNA as a probe was performed in order to exclude genomic rearrangements and/or intronic mutations. In addition a RT-PCR of PRX-IV was performed in order to investigate expression alterations.

Results: No causative mutations were found. Two adjacent nucleotide substitutions were detected within introns $I$ and 4 . These changes were also detected in unaffected individuals, suggesting that they were innocuous polymorphisms. No gross genomic rearrangements and/or restriction fragment alterations were observed on Southern analysis. Finally, using RT-PCR from tissue-specific RNA, no differences of PRX-IV expression-levels were detected between affected and unaffected samples.
\end{abstract}

Conclusions: Based on sequence and genomic analysis, Prx-IV is very unlikely to be the MNG2 gene. 
Table I: Forward and reverse PCR primers used for amplification of the coding and promoter regions of PRX-IV

\begin{tabular}{lllll}
\hline Exon number & Exon size (bP) & cDNA position & Primer sequence & PCR size \\
\hline & & & & \\
1 & 241 & $\mathrm{I}$ & $\mathrm{F}$ taggtgagaaccaggccegcccagg R gtcgtgcacgcggttgtagctgc & 457 \\
2 & 118 & 242 & $\mathrm{~F}$ ataatttgttgatactcctg R ctgccaaagagatctaaaggtagc & 307 \\
3 & 117 & 360 & F gctattcctgaattgtctg R acagtcttttagactactcc & 396 \\
4 & 123 & 477 & F ttgagctaccgtgcctggc R aggtaagcgttctgtttg & $28 I$ \\
5 & 131 & 608 & F gtaaataatcagaaactttgg R gcatccttttgtgtggatgg & 326 \\
6 & 35 & 643 & Fctcctgacctcgtgatctgc R gctgaaggtaactgaattctg & 226 \\
7 & 48 & 691 & F tttggcatcagtgtctaacgc R tttagtcaggcatgggc & 298 \\
cDNA & & 13 & F caagggacgtgtttctgcgc R cagctggatctgggattatc & 815 \\
Promoter region & & -936 & F gctgtctttgaacaatag R tgtatacattcgtgggatgc & 475
\end{tabular}

\section{Background}

Multinodular goiter (MNG, OMIM *138800) is a common disorder, arising as a compensatory response to an impairment of thyroid hormonogenesis. Affected individuals maintain normal hormone levels by an increase in thyroid activity and mass, so that they are eu-metabolic but goitrous [1]. Even if MNG incidence is influenced by iodine intake, family clustering of the disease has been reported in iodo-sufficient areas, suggesting a genetic basis for the disease [2]. This was confirmed by the identification of three dominant MNG loci: MNG1 on chromosome 14q [3], MNG2 on chromosome Xp22 [4] and MNG3 on chromosome $3 q 26$ [5]. The MNG2 locus maps to a $9.6 \mathrm{cM}$ interval containing the peroxiredoxin-IV (PrxIV, formerly known as AOE372) gene. Peroxiredoxins are a family of highly conserved anti-oxidant enzymes, reducing hydrogen peroxide and/or organic hydroperoxides [6]. In thyroid cells, regulation of $\mathrm{H}_{2} \mathrm{O}_{2}$ concentration is critical for the thyroxine synthesis, since hydrogen peroxide is needed for the conversion of iodide to organically bound iodine. Since PRX-I e PRX-II are involved in the removal of $\mathrm{H}_{2} \mathrm{O}_{2}$ in thyroid cells, we have hypothesised that Prx-IV mutations may affect intracellular $\mathrm{H}_{2} \mathrm{O}_{2}$ levels and impair thyroxine hormonogenesis. Therefore, we have screened Prx-IV as a MNG2 positional candidate.

\section{Methods}

\section{Direct sequencing}

We have sequenziated four individuals ( 2 affected, 2 unrelated unaffected) originated from the large family that allowed the MNG2 locus assignment [4].

Intronic primers pairs amplifying Prx-IV exons were designed (Table 1), based on the genomic structure reported by Wong et al.[6]. One primers pair amplifying $500 \mathrm{bp}$ of putative promoter was also selected (Table 1). Intron and 5 'UTR sequences were obtained, using the BLAST program to match Prx-IV mRNA (accession n. XM_041446) against the "htgs" database of genomic sequences. The most likely location of the promoter was assessed using the SCAN SIGNAL software. PCR products were sequenced with the $\mathrm{CEQ}^{\mathrm{TM}}$ DTCS Kit (Beckman-Coulter, CA, USA) and run on a CEQ2000 automated sequencer (Beckman-Coulter, CA, USA).

\section{Southern blot}

$5 \mu \mathrm{g}$ genomic DNA were digested using EcoRI and Hind III. Digests were electrophoresed on $1.0 \%$ agarose gels, and the DNA was subsequently transferred to Hybond N+ filter membranes (Amersham), with $10 \times$ SSC as transferring buffer. Probes were labeled, by random priming, with 32P-dCTP. Membranes were hybridized overnight at $65^{\circ} \mathrm{C}$. Final washing of the membranes was performed with $0.1 \times \mathrm{SSC}$ at $65^{\circ} \mathrm{C}$. The results were analyzed with the STORM Phosphor Imaging System.

\section{FNAB and RT-PCR}

Patients were placed in the recumbent position with a pillow under their shoulders, such that their neck was hyperextended, and the skin cleansed with povidone iodine (Betadina scrub). The nodules was fixed in position manually, and a 23 gauge needle attacched to a $20 \mathrm{ml}$ disposable syringe inserted perpendicular to the anterior surface of the neck. Once the needle was in place, costant suction was applied and maintained while the needle was withdrawn to the level of the nodules capsule. The content was then discharged onto glass slides and smears were made.

FNAB samples were then washed twice with $1 \times$ PBS and then processed for RNA extraction. Approximately $1 \mu \mathrm{g}$ of RNA was incubated at $42^{\circ} \mathrm{C}$ for 1 hour with $2.5 \mu \mathrm{M}$ random hexamers (Pharmacia, LKB, Uppsala), $25 \mathrm{U}$ of Rnase inhibitor (Rnasin, Promega, Madison, WI), $2.5 \mu \mathrm{l}$ of 10 $\mathrm{mM}$ each dNTPs, $4 \mu \mathrm{l}$ of $5 \times$ AMV RT (Promega, Madison, $\mathrm{WI}$ ) in a final volume of $20 \mu \mathrm{l}$. The cDNA was next amplified by PCR for PRX-IV gene using primers showed in ta- 
ble 1. As a positive control we coamplified the constitutively expressed enzyme glyceraldeide 3-phosphate dehydrogenase (GAPDH).

The intensity of the amplified fragments was compared by scanning using a Molecular Dynamics (Sunnyvale, CA) densitometer (ImageQuant).

\section{Results}

We have carried out Prx-IV mutational analysis in the three-generation Italian pedigree that allowed the MNG2 locus assignment [4]. Prx-IV is a cytoplasmatic thioredoxin peroxidase that detoxifies hydrogen peroxide in a redox chain leading to NADPH oxidation [7]. Therefore, Prx-IV appears an attractive MNG candidate, since thyroxine synthesis requires hydrogen peroxide.

Patient sequencing identified two adjacent substitutions in intron 1 (IVS1-9G $>\mathrm{A}$ and IVS1-10A $>$ T), and one in intron 4 (IVS4+81T>C). All variants were also found in one unrelated unaffected male, thus ruling out the hypothesis that any of them might be disease-related. Coding region analysis failed to detect any additional substitutions and moreover promoter region analysis didn't detect other substitutions. Since the affected females carrying both alleles at intron 2 variants, the occurrence of a large gene deletion can be excluded. In addition, as shown in figure 1, no gross PRX-IV rearrangements were detected by Southern blot analysis.

Expression analysis using amplified PRX-IV cDNA revealed a single PCR product of the expected size. An equal relative ratio of intensity with a value 0.86 was detected when this product was compared with GAPDH cDNA used as a control (Data not shown).

\section{Discussion and Conclusions}

Altogether our data indicate that Prx-IV is very unlikely to be the MNG2 gene.

The MNG2 region does not contain any additional obvious candidate, but many ESTs map to the critical interval. Thus, our future research will be devoted to the identification and characterization of those MNG2 ESTs that are expressed in the thyroid.

\section{List of abbreviations used}

MNG : multinodular goitre

PRX : peroxiredoxin

EST : expressed sequence tag

FNAB : fine needle aspiration biopsy

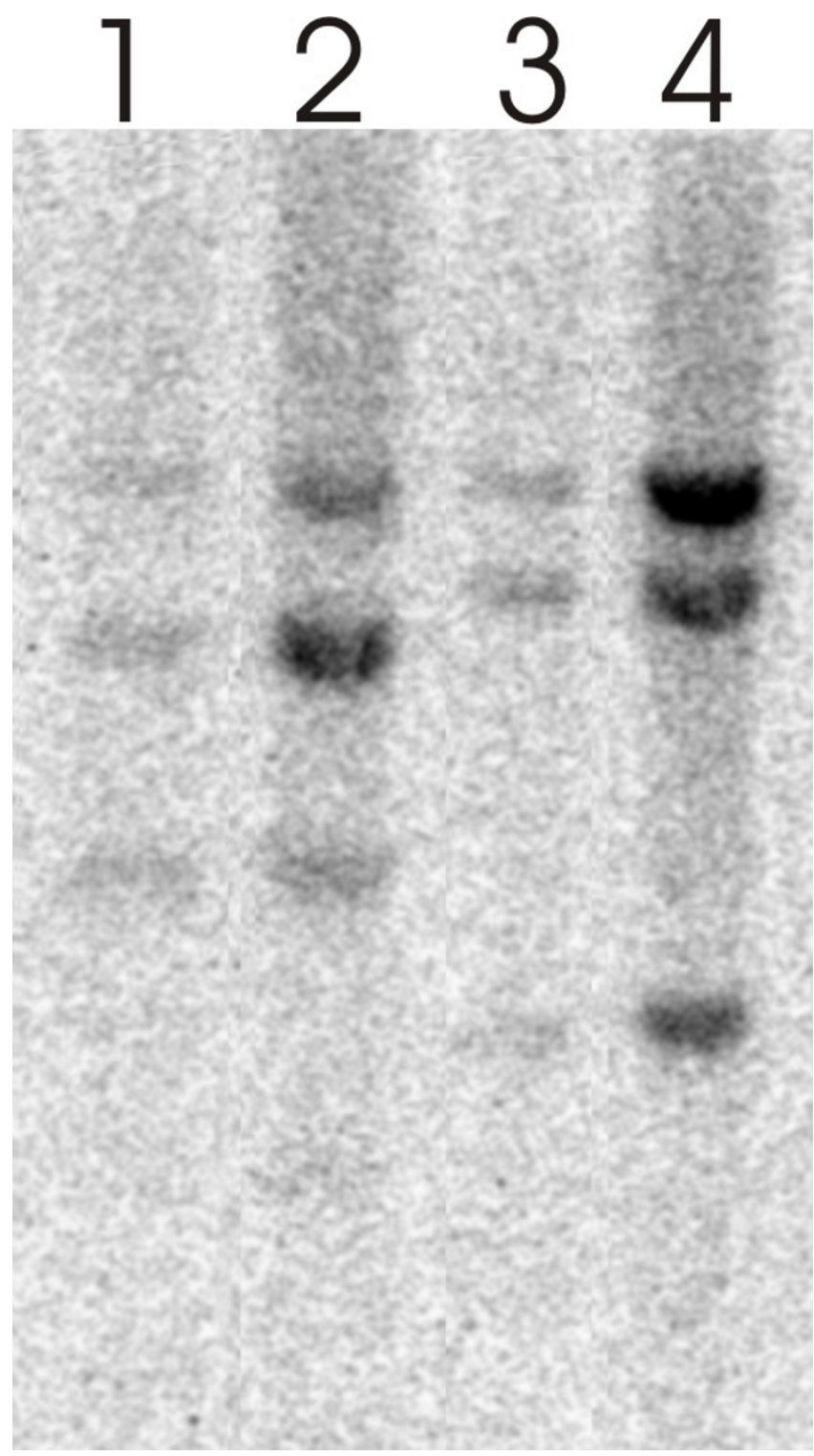

Figure I

Southern-blot analysis. Lane I,3 : genomic DNA from a patient (L.F.) affected with Multinodular goitre digested respectively with EcoRI and HIND III. Lane 2,4 : genomic DNA from a normal control digested respectively with EcoRI and HIND III.

\section{Competing interests}

None declared

\section{Acknowledgements}

This work was funded by the Italian Telethon (project EI03I).

\section{References}

I. Ingbar SH, Woeber KA: The thyroid gland. In: Textbook of endocrinology. (Edited by: Williams RH) WB Saunders, Philadelphia 1968, 105279 
2. Greig WR, Boyle JA, Duncan A: Genetic and non-genetic factors in simple goitre formation: evidence from a twin study. $Q J$ Med 1967, 36:175-188

3. Bignell GR, Canzian F, Shayeghi M, Stark M, Shugart YY, Biggs P, Mangion J, Hamoudi R, Rosenblat J, Buu P, Sun S, Stoffer SS, Goldgar DE, Romeo G, Houlston RS, Narod SA, Stratton MR, Foulkes WD: Familial non toxic multinodular goitre locus maps to chromosome $14 \mathrm{q}$ but does not account for familial non medullary thyroid cancer. Am J Hum Genet 1997, 6 I: I I 23- I I30

4. Capon F, Tacconelli A, Giardina E, Sciacchitano S, Bruno R, Tassi V, Trsichitta V, Filetti S, Dallapiccola B, Novelli G: Mapping a dominant form of multinodular goitre to chromosome Xp22. Am J Hum Genet 2000, 67:1004-1007

5. Takahashi T, Nozaki J, Komatsu M, Wada Y, Utsunomiya M, Inoue K, Takada G, Koizumi A: A new locus for a dominant form of Multinodular goiter on 3q26.I-q26.3. Biochem Biophys Res Commun 200I, 284:650-654

6. Wong CM, Chun ACS, Kok KH, Zhou Y, Fung PCW, Kung HF, Jeang $K T$, Jin DY: Characterisation of human and mouse peroxiredoxin IV: evidence of inhibition by Prx-IV of epidermal growth factor- and $\mathrm{p} 53$-induced reactive oxygen species. Antioxid Redox Signal 2000, 2:507-5I8

7. Jin DY, Chae HZ, Rhee SG, Jeang KT: Regulatory role for a novel human thioredoxin peroxidase in NF-KB activation. J Biol Chem 1997, 272:30952-3096।

\section{Pre-publication history}

The pre-publication history for this paper can be accessed here:

http://www.biomedcentral.com/1471-2350/3/5/prepub

Publish with BioMed Central and every scientist can read your work free of charge

"BioMedcentral will be the most significant development for disseminating the results of biomedical research in our lifetime."

Paul Nurse, Director-General, Imperial Cancer Research Fund

Publish with BMC and your research papers will be:

- available free of charge to the entire biomedical community

- peer reviewed and published immediately upon acceptance

- cited in PubMed and archived on PubMed Central

- yours - you keep the copyright

Submit your manuscript here:

http://www.biomedcentral.com/manuscript/
BioMedcentral.com editorial@biomedcentral.com 